\title{
Pengaruh Proses Islamisasi dalam Bidang Arsitektur di Indonesia
}

Mahmuda

Institut Agama Islam Negeri Batusangkar, Sumatera Barat, Indonesia

E-mail: mahmuda@iainbatusangkar.ac.id

\begin{abstract}
Abstrak: Kajian ini diawali oleh banyaknya khazanah pemikiran keislaman, yaitu isu tentang Islamisasi dalam hal disiplin ilmu, arsitektur bahkan dalam berbagai tatanan sosial masyarakat di Indonesia yang merupakan salah satu isu yang selalu menarik diperbincangkan beberapa dekade ini. Hal ini terjadi karena ada berbagai pandangan dan penafsiran tentang Islamisasi. Konsep ini meniscayakan umat Islam untuk memahami realitas secara utuh. Islamisasi adalah proses peralihan masyarakat menjadi Islam baik terpengaruh dalam keagaman atau kepercayaan, budaya, sosial kemasyarakatan ekonomi maupun dalam bidang politik, yang dalam bahasa lain disebutkan sebagai mengislamkan masyarakat yang disebabkan karena kedatangan ajaran agama Islam. Oleh sebab itu penulis ingin mengkaji bagimana proses islamisasi yang terjadi pada masyarakat indonesia sehingga dapat tercermin bahakan menjadi karakter islamisasi yang di seluruh wilayah indonesia, seperti halnya islamisasi dalam hal arsitektur ditinjau dari aspek bangunan fisik seperti Masjid, Batu Nissan, hingga dalam bentuk seni kaligrafi
\end{abstract}

Abstract: This study was initiated by the many treasures of Islamic thought, namely the issue of Islamization in terms of scientific disciplines, architecture and even in various social structures of society in Indonesia, which is one of the issues that has always been interestingly discussed in recent decades. This happens because there are various views and interpretations of Islamization. This concept requires Muslims to fully understand reality. Islamization is the process of converting society to Islam, whether influenced by religion or belief, culture, socio-economics, or in the political field, which in other languages is referred to as Islamizing society due to the arrival of Islamic teachings. Therefore, the author wants to examine how the process of Islamization occurs in Indonesian society so that it can be reflected even into the character of Islamization throughout Indonesia, such as Islamization in terms of architecture in terms of aspects of physical buildings such as mosques, Stone Nissan, to the form of calligraphy art.

Kata Kunci: Islamisasi, Arsitektur, Indonesia

\section{PENDAHULUAN}

Islam adalah salah satu agama yang diakui secara global, dan tentunya banyak membawa perubahan bagi pengikut maupun kedalam tatanan dunia, baik dalam hal segi religi, sosial, maupun perkembangan ekonomi dan masalah politik dewasa ini.

Kesemuanya banyak diatur dalam agama Islam, tidak terkecuali kepada masyrakatnya yang tentu harus mengikuti Islam sebagai agama yang diyakini dan dijadikan pegangan hidup bermasyarakat. 
Sebagaimana telah Allah sampaikan melalui kitabnya di dalam alQuran (al-Baqarah 2: 256)

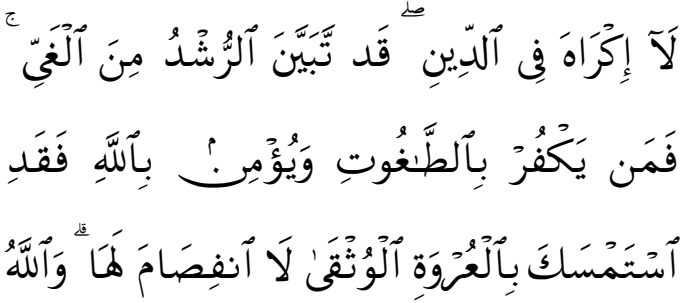

سَمِيْعُ عَلِيمُ

Tidak ada paksaan untuk (memasuki) agama (Islam), sesungguhnya telah jelas jalan yang benar daripada jalan yang sesat. karena itu Barangsiapa yang ingkar kepada Thaghut, dan beriman kepada Allah, Maka Sesungguhnya ia telah berpegang kepada buhul tali yang Amat kuat yang tidak akan putus. dan Allah Maha mendengar lagi Maha mengetahui.

Melihat dari sejarah

perkembangan Islam yang cukup lama

sejak masa permulaan timbulnya Islam, tersebarnya Islam di belahan dunia baik di Asia, Afrika, Eropa maupun sampai kepada kawasan Asia Tenggara dan sampai sekarang telah tersebar luas di negara kita Indonesia. Tentunya Islam adalah suatu model perubahan agama baru yang dianut oleh bangsa Indonesia yang dimulai dari kedatangan agama Hindu dan Budha, serta menyusul agama-agama pendatang seperti Islam, Kristen katolik, Protestan, dan Konghucu.
Saat sekarang ini kemajuan ilmu pengetahuan di dunia Islam terus mengalami degradasi atau penurunan dan bahkan terus memudar seiring dengan adanya kekuatan politik di kalangan negara muslim yang tidak kunjung selesai dan terus mengalami perselisihan. Sehingga dunia Islam sadar akan keterbelakangannya baik dalam peradaban serta ilmu pengetahuan.

Istilah 'Islamisme' pertama kali dikemukakan oleh seorang filsuf Prancis terkemuka, Voltaire, sebagai pengganti kata mahometisme yang ketika itu dipakai sebagai acuan untuk 'agama orang Arab' di kalangan orang Eropa. Kata ini lalu diadopsi ke dalam bahasa Inggris pada edisi 1900 Oxford English Dictionary. Akan tetapi setelah itu istilah ini sekian lama jarang digunakan. Akhir-akhir ini ketika Islam politik menjadi topik utama dalam politik internasional Pascaperang Dingin, Islamisme sekali lagi menjadi istilah yang dipakai secara luas oleh para sarjana dan wartawan. Sekarang secara umum istilah itu mengacu pada jenis tertentu dari interpretasi agama, organisasi dan gerakan di kalangan umat Islam yang menekankan keunikan 
dan keunggulan Islam vis-à-vis ideologi politik lainnya. Istilah Islamisme sering juga dipertukarkan dengan istilah fundamentalisme dan salafisme.

Islamisasi adalah proses peralihan masyarakat menjadi Islam.

Dalam penggunaan kontemporer, mungkin mengacu pada pengenaan dirasakan dari sistem sosial dan politik Islam di masyarakat dengan latar belakang sosial dan politik pribumi yang berbeda.

Dalam arti sebenarnya menurut kamus besar bahasa Indonessia (KBBI) Arsitektur yakni seni atau ilmu merancang serta membuat konstruksi bangunan, jembatan, dan sebagainya.

Indonesia adalah salah satu negara dikawasan Asia Tenggara (Assosiation of East Asia Nations), yang merupakan bagian negara yang mayoritas penduduknya beragama Islam yang dalam penyebarannya tidak terlepas dari proses islamisasi baik dalam bidang keyakinan atau agama, sosial, maupun perkembangan ekonomi, arsitektur dan politik.

\section{METODE PENELITIAN}

Penelitian ini menggunakan kepustakaan, yang kemudian dijelaskan dengan menggunakan metode content analisis.

\section{HASIL DAN PEMBAHASAN}

\section{Islamisasi Menurut Para Tokoh Islam dan Tokoh Kontemporer}

\section{Islamisasi Menurut al-Attas}

Syed Muhammad Naquib Ibn Ali Ibn Abdullah Ibn Muhsin Al-Attas lahir pada tangga 5 September 1931 di Bogor Jawa Barat. Ayahnya bernama Syed Ali Al-Attas yang berasal dari Saudi Arabia yang masih termasuk bangsawan di Johor. Ayahnya memiliki silsilah keturunan dari ahli tasawuf yang sangat terkenal dari kelompok sayyid dengan silsilah yang sampai pada Imam Hussein, cucu Nabi Muhammad. Sedangkan Ibunya bernama Syarifah Raquan Al-Aydarus (AlIdrus), berasal dari Bogor Jawa Barat dan merupakan keturunan Ningrat Sunda di Sukapura.

Dari Pihak ayah, Muhammad Naquib Al-Attas memiliki kakek yang bernama Syed Abdullah ibn Muhsin ibn Muhammad Al-Attas adalah seorang wali yang berpengaruh di Indonesia dan Arab. Sedangkan neneknya, Ruqayah Hanum adalah wanita Turki berdarah Aristocrat yang menikah dengan Ungku 
Abdul Majid, adik sultan Abu Bakar Johor pada tahun 1895.

Menurutnya kebangkitan Islam bukan berarti menolak kehidupan modern. Al-Attas justru mendorong masyrakat islam untuk menjalani arus kehidupan modern yang memang tak terbendung. Sehingga Islam dapat mengartikan ajarnnya dalam semua kehidupan. Sehingga munculnya proses islamisasi kehidupan modern di kalangan masyarakat islam

\section{Ismai'il Raji al-Faruqi}

Isma'il Raji Al-Faraqi merupakan ilmuan muslim terkemuka pendiri pusat pengkajian Islam di Temple University Philadelphia, AS. Beliau dilahirkan di Jaffa, sebuah daerah di Palestina, ketika Palestina belum direbut oleh Israel. Dia dilahirkan pada tanggal 1 Januari 1921 (Van Hoeve, 1993: 334).

\section{Adapun Isma'il Raji Al-Faruqi} dapat ditempatkan pada kelompok muslim yang ketiga. Konsep Islamisasi Pengetahuan yang dicanangkannya mempunyai pengaruh besar kepada para intelektual muslim lain, seperti Ja'far Syaikh Idris dari Sudi Arabia Osman Bakar dari Malaysia dan sebagainya. Menurut pandangan Ismai'il Al Faruqi umat Islam waktu itu dalam keadaan yang lemah (Jalaluddin dan Usman Said, Tth :159). Kemerosotan muslim dalam zaman kemunduran menyebabkan kebodohan. Di kalangan kaum muslim berkembang buta huruf, kebodohan dan tahayul. Akibatnya muslim yang awam lari dari keyakinan, yang buta huruf bersandar kepada literalisme dan legalisme atau menyerahkan diri kepada pemimpin mereka. Sehingga umat menjadi fanatik secara harfiyah kepada Syari'at dan meninggalkan sumber kreativitas.

Zaman kemunduran dalam berbagai bidang kehidupan, terutama bidang ekonomi telah menempatkan umat Islam berada di anak tangga bangsa-bangsa yang terbawah. Dalam keadaan seperti ini masyarakat muslim melihat kemajuan Barat sebagai sesuatu yang mengagumkan. Hal ini menyebabkan sebagai kaum muslimin tergoda oleh kemajuan barat tersebut dan berupaya untuk mengadakan reformasi dengan cara westernisasai. Ternyata jalan yang ditempuh itu menghancurkan umat Islam itu sendiri. Keadaan tersebut menyebabkan integritas kultur Islam terpecah dalam diri mereka sendiri, terpecah dalam 
pemikiran, perbuatan dalam rumah tangga dan keluarga.

\section{Ziaudin Sardar}

Ziauddin Sardar adalah seorang intelektual Muslim yang juga seorang penulis Islam progresif dan penulis kajian pemikiran Islam kontemporer, seorang saintis dan kritikus budaya. Sardar dilahirkan pada tahun 1951 di Punjab Pakistan, besar di Hackneyh, kawasan timur London dan bermukim di Inggris

Menurutnya Islamisasi bukanlah sekadar sistesis ilmu-ilmu modern dengan ilmu-ilmu Islam. Islamisasi harus dimulai dari aspek ontologi denganmembangun world view dengan berpijak pada epistemologi Islam. Tanggapan berbeda disampaikan oleh kelompok yang tidak setuju dengan Islamisasi ilmu. Kelompok yang kontra beranggapan bahwa Islamisasi ilmu merupakan pekerjaan.

\section{Islamisasi Rumah Ibadah (Masjid) di Indonesia}

Istilah masjid berasal dari kata sajada-yasjudu yang berarti bersujud atau menyembah. Kata masjid merupakan bentuk mufrad (tunggal). Sedangkan jama' (banyak) masâjid banyak terdapat dalam Alquran, antara lain dalam ayat berikut ini:

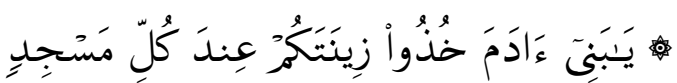
"Hai Anak Adam pakailah pakaianmu yang indah di setiap (memasuki) masjid..." (QS Al-A'raaf [7]: 31).

Berbicara tentang potensi dan fungsi masjid memang sangat banyak dan sama banyaknya ketika membicarakan permasalahan masjid. Sebagai bagian awal akan dibicarakan potensi dan fungsi masjid. Pertama, masjid berfungsi sebagai tempat ibadah seperti, shalat, dzikir, dan mengaji. Fungsi ini menjadikan masjid sebagai tempat pemenuhan kebutuhan rohani umat. Kedua, masjid mempunyai fungsi penyelesaian masalah dibidang sosial. Lewat kegiatan yang bersifat bantuan langsung kepada masyarakat seperti, pemberian santunan bagi fakir, miskin, dan anak terlantar, dan pemberian bantuan di bidang kesehatan. Ketiga, di bidang pendidikan masjid juga memiliki potensi yang luas. Lewat kegiatan seperti, kajian Islam, pengajaran AlQur'an bagi anak-anak hingga dewasa masjid akan berkontribusi bagi pendidikan. Keempat, masjid mempunyai potensi ekonomi; apabila potensi zakat, infaq, dan shadaqah umat 
dikelola dan disalurkan untuk bantuanbantuan usaha produktif masyarakat atau untuk pendirian lembaga keuangan syari'ah ataupun koperasi. Kelima, masjid juga dapat membentuk karakter masyarakat menjadi lebih baik. Masyarakat yang berbaur dan bertemu di masjid ketika shalat jama'ah atau kegiatan kajian Islam dapat saling mengenal dan menimbulkan kerukunan sosial yang kuat. Ketika si miskin dan si kaya bertemu di masjid akan terjadi interaksi saling bantu membantu. Bahkan saat masjid akan dibangun masyarakat akan bergotong-royong mengumpulkan dan mengorbankan sumber daya yang dimiliki demi berdirinya sebuah masjid.

Membahas tentang masjid sebagai salah satu rumah ibadah yang ada di indonesia juga tidak terlepas dari perkembangan Islam yang sudah masuk dan telah menginjak kakinya di bumi Nusantra ini. Pada awal kedatangan Islam di sekitar abad ke 13 di Indonesia banyak cara -cara yang dilakukan oleh para pendakwah agama untuk menyebar agama ini, baik oleh para pedagang dari India maupun asli dari para pendakwah Islam yang di utus melalui daerah jazirah Arab hingga sampailah ke daerah pesisir timur sumatera.

Proses Islamisai yang mereka lakukan berbagai macam cara diantaranya adalah, dengan cara melalui perdagangan, melalui perkawinan, pengajaran aliran tasawuf, melalui aliran pendidikan, aliran kesenian, hingga poklitik.

Disini peneliti menilai berbagai macamara islamisai yang dilakukan saat itu, guna menjadikan agama Islam sebagai agama yang telah ada, serta ada pengikutnya yang menandakan islam sudah ada di Indonesia. Dalam proses islamisasi ini sebagai wujud dan bentuk yang nyata dimana masjid sebagai salah satu tempat berkumpulnya para muslim dan muslimat yang hendak melakukan ibadah kepada Tuhan (Allah), memberikan kontribusi yang maksimal kepada masyrakat Indonesia pada waktu itu, dan memberikan sutu pemahaman kepada masyarakat dimana sebagai agama yang baru islam juga memiliki tempat ibadah yang dinamakan sebagai masjid.

Proses awal masjid berdiri dalah sebagai bangunan biasa dan seiring waktu dan terus melakukan dakwah agama di Indonesia, maka secara tidak 
langsung masjid sudah menjadi bagian islamisai di Indonesia dalam bentuk bangunan atau arsitektur. Kita ketahui bersama bahwa sepanjang masjid telah berdiri di suatu daerah maka serta merta ajaran agama Islam sudah masuk di wilayah tersebut dan menjadikan penyebaran agama islam telah sampai dan penduduknya menjadikan masjid sebagai identitas daerah tersebut sudah adayang beragama Islam. Pembangunan masjid bukan hanya sekedar bangunan fisik saja, tetapi memiliki makna yang tersirat didalamnya. Banyak pembangunan masjid di Indonesia terinspirasi dari pilar islami yang terkandung dalam 2 kalimat syahadat, sejarah para sahabat rasululullah dan juga banyak melahirkan tanda-tanda ke islaman yang dituangakan dalam setiap pembangunan masjid di Indonesia. Seperti halnya masjid-masjid besar atau agung di seluruh wilayah indonesia. Contoh masjid dinataranya adalah:

\section{Masjid Mantingan}

Masjid Mantingan dibangun sejak berdirinya Kesultanan Demak di tanah Jawa. Berlokasi di desa Mantingan, Kecamatan Tahunan, Kabupaten Jepara, Jawa Tengah, masjid Mantingan memiliki arsitektur yang unik karena menyerupai klenteng atau bangunan khas tiongkok lainnya. Masjid ini menjadi saksi penyebaran Islam di Kabupaten Jepara, tepatnya di Kecamatan Tahunan yang kala itu dihuni oleh etnis China.

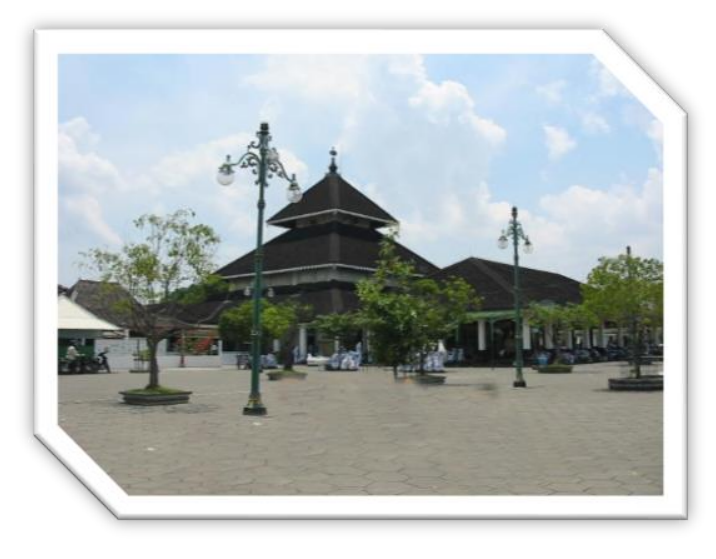

\section{Masjid Agung Banten}

Masjid Agung Banten dibangun pada masa pemerintahan Sultan Maulana Hasanuddin pada tahun 1552. Arsitekturnya cukup unik karena memiliki atap bertumpuk lima yang hampir mirip dengan pagoda China. Terdapat satu menara besar yang menjulang tinggi untuk mengumandangkan adzan pada zaman dahulu.

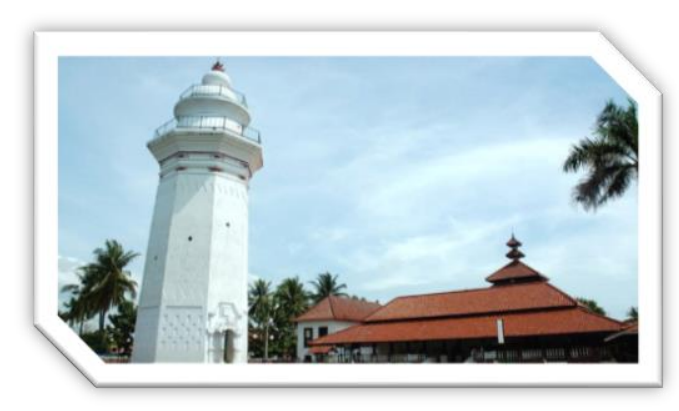




\section{Masjid Menara Kudus}

Masjid Menara Kudus terletak di Desa Kauman, Kecamatan Kota, Kabupaten Kudus. Masjid ini dibangun oleh Sunan Kudus pada tahun 1549. Keunikan Masjid Menara Kudus terletak pada bangunan menaranya yang menyerupai candi khas Hindu. Konon menara ini dibangun agar umat muslim di Kudus yang mualaf dari agama Hindu tidak mengalami culture shock saat memasuki kawasan masjid.

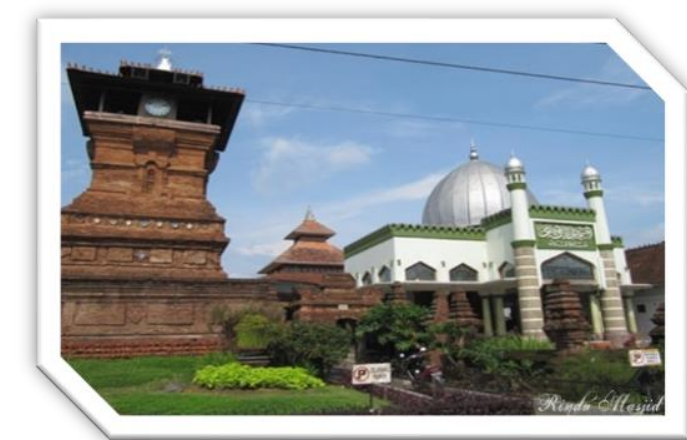

Masjid Raya al-Maksum

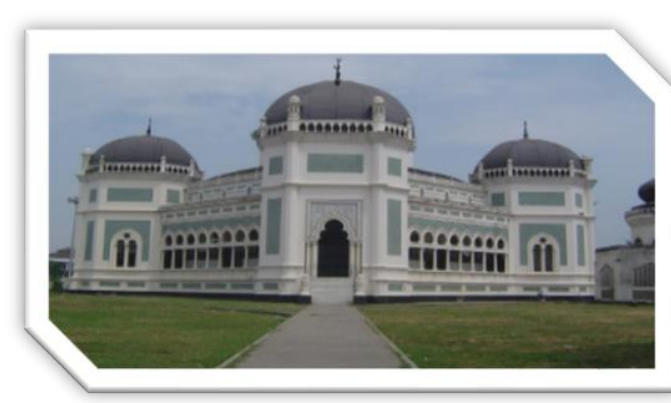

Masjid Raya al-maksum ini dibangun mulai tahun 1906 masehi dan selesai hingga 1909 M, dan sampai sekarang tetap mengalami pembugaran disebabkan oleh waktu yang sudah begitu lama. Pada masa penjajahan tempo dulu, umat Islam khususnya di Medan, sangat bersyukur sebab wilayah kekuasaan kesultanan Deli tidak begitu luas sehingga sultan Ma'amun AlRasyid tetap mampu membangun sebuah masjid yang teramat indah dan megah untuk ukuran masa itu. Sultan Ma'amun berprinsip, lebih mengutamakan kemegahan masjid dari pada istananya sendiri. Hal seperti ni mencerminkan bahwa orang melayu sudah banyak memleuk agama Islam bahkan melayu adalah identik dengan keislman. Dan tentunya masih banyak lagi masjid-masjid di Indonesia yang menjadi ikon dalam penyebaran agama Islam dan sebagai tandan islamisai terjadi di wilayah Indonesia.

\section{Islamisasi Batu Nisan (Tanda Kuburan Muslim) di Indonesia}

Bukti arkeologi yang lebih tua dari yang telah ditemukan di daratan Sumatera adalah temuan dua batu nissan di daerah leran (Jawa Timur), yang mana mempunyai angka tahun $496 \mathrm{H} /$ $1102 \mathrm{M}$ yang di tulis dalam gaya tulisan kahfi yang oleh J.P Moqquete di baca Fatimah binti Maimun, yang kedua tahun 1391 dibaca dengan nama putri Suwari. 
Ada perkiraan bahwa islam masuk ke nusantara tidak hanya melalui jalur "Barat" yakni Arab, Persia, pantai barat India dan Aceh, tetapi juga melalui jalur "Timur" yakni dari Tiongkok, campa dan jalur pantai timur lainnya seperti Malaka, Trengganu danakhirnya ke Jawa. Kesimpulan dari laporan Marcopolo adalah dapat dipastikan bahwa Perlak sudah masuk islam sebelum 13 atau 1292 M, dan dilihat dari adanya batu Nisan Malik al-Saleh pada tahun 1297 M. sudah dapat dipastikan bahwa Malik al-Saleh adalah seorang raja. Pada gambar di bawah ini adalah salah satu contoh batu nisan yang ada di Barus di Kab. Tapanuli Tenggah Sumatera Utara yang berkisar diantara $44 \mathrm{H}-48 \mathrm{H}$.

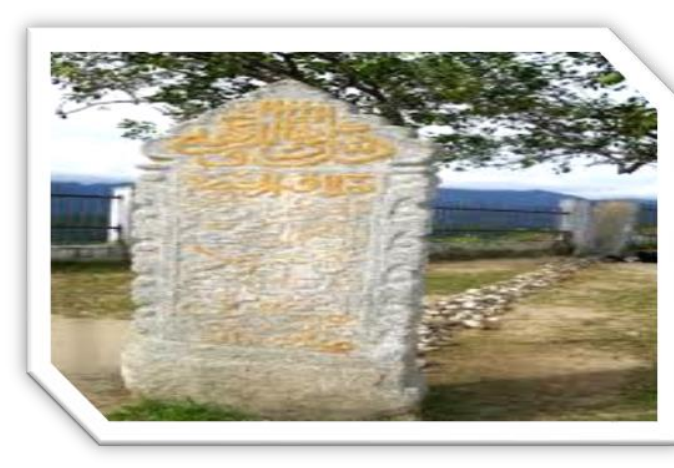

Dari pembuktian dari berbagai literatur yang ada telah jelas bahwa banyak cara yang dilakukan islam dalam proses islamisasi di Indonesia, yang di tandai juga adanya bukti tertulis dan bangunan seperti nisan yang terletak dimakam setiap muslim. Hal ini menunjukan bahwa proses islamisasi di lakukan dengan berbgai cara seperti batu nisan di setiap kuburan raja maupun masyarakat yang sudah notabane telah sah dan mutlak menganut agama islam.

Hampir seluruh wilayah indonesia yang masyarakatnya menganut agama islam, didalam proses penandaan kuburan atau tempatnya di tandai dengan berdirinya batu nisan sebagai pertanda bahwa yang terkubur atau yang telah meninggal tersebut merupakan seorang yang beragama islam.

\section{Islamisasi karya seni (Kaligrafi) di Indonesia}

Sebelum kedatangan islam di Nusantra atau Indonesia banyak karya seni yang yang sudah ada di khalayak masyarakat pada saat itu, seperti halnya tulisan jawa kunno (Jawi), ada juga tulisan suku-suku asli maupun bentuk arkeologi yang terpengaruh dari agama Hindu dan Budha yang merupakan bentuk awal penyebaran agama di Nusantara. Namun setelah Islam masuk dan datang sebagai agama dan pembaharuan masyarakat, sebahagian seni telah di ubah karena seni yang pada 
saat itu seperti memahat batu, kayu dirubah menjadi bentuk manusia atau makhluk hidup yang kesemuanya tersebut mendapat perubahan karena bertentangan dengan ajaran agama. Setelah Islam masuk maka proses islamisasi seni dirubah kedalam bentuk seni lainnya.

Tampak jelas diantaranya adalah dengan adanya berbagai gaya seni berupa kaligrafi yang tertulis di setiap bangunan dinding baik, di area masjid, maupun didalam ruangan perkantoran dan tempat tingggal. Karya seni kaligrafi ini adalah suatu pertanda bahwa Islam telah masuk ke wilayah indonesia dan telah membaur sehingga unsur kesinian Islam telah diterima oleh seluruh masyarakat yang sudah memeluk agama islam. Banyak jenis kaligrafi yang mencerminkan keindahan dalam setiap penulisannya diantaranya adalah: Khat Naskhi, Khot Riq'a, Khot Diwani, Khot Kufi Murabba, Khot Tsuluts, Khot Farisi.
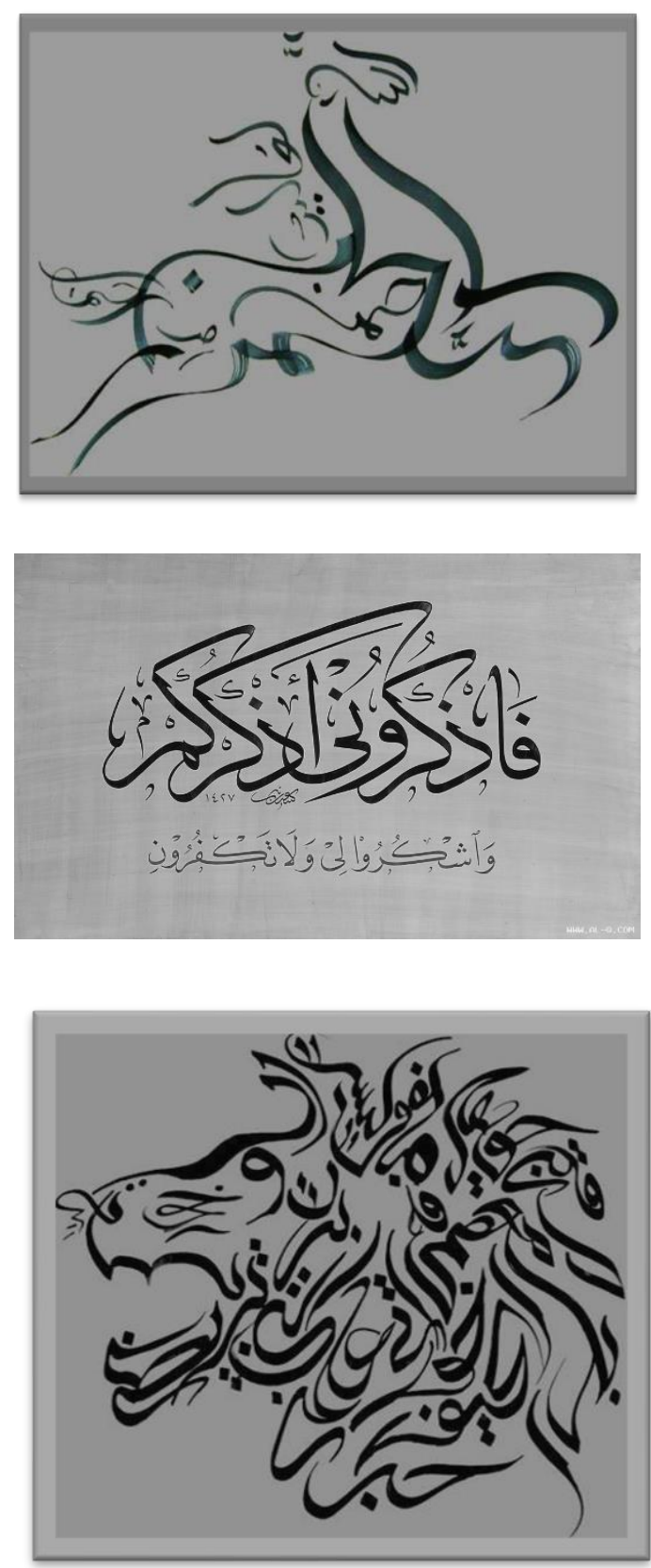

Kaligrafi juga terhubung dengan ayat-ayat Tuhan (al-Quran) yang mengingatkan para pemeluknya dalam segala sesuatu baik dalam hal ketauhidan, kedesiplinan ibadah, dan juga ancaman dari Allah sang maha kuasa kepada hamba-hambanya. Fungsi 
kaligrafi sebagai uapaya dalam islamisasi budaya yang berdasarkan keagamaan ini menimbulkan cara pandang masyarakat yang merupakan sebagai identitas diri, kelompok maupun masyarakat di daerah tersebut yang sudah meemeluk agama islam sebagai pegangan hidupnya.

\section{KESIMPULAN}

Adapun yang menjadi kesimpulan dari pemabahasan proses islamisasi arsitektur di Indonesia di antaranya adalah:

Islamisasi adalah proses peralihan masyarakat menjadi Islam. Dalam penggunaan kontemporer, mungkin mengacu pada pengenaan dirasakan dari sistem sosial dan politik Islam di masyarakat dengan latar belakang sosial dan politik pribumi yang berbeda.

Dalam proses islamisasi ini sebagai wujud dan bentuk yang nyata dimana masjid sebagai salah satu tempat berkumpulnya para muslim dan muslimat yang hendak melakukan ibadah kepada Tuhan (Allah), memberikan kontribusi yang maksimal kepada masyrakat Indonesia pada waktu itu, dan memberikan sutu pemahaman kepada masyarakat dimana sebagai agama yang baru islam juga memiliki tempat ibadah yang dinamakan sebagai masjid.

Kita ketahui bersama bahwa sepanjang masjid telah berdiri di suatu daerah maka serta merta ajaran agama Islam sudah masuk di wilayah tersebut dan menjadikan penyebaran agama islam telah sampai dan penduduknya menjadikan masjid sebagai identitas daerah tersebut sudah beragama Islam.

Islam sebagai agama yang rahamatan lil alamin, menajadi acuan bahwa islam telah memberikan kontribusi penting dalam setiap perubahan masyrakat pribumi baik dari aspek sosial, ekonomi, politik dan arsitektur sebagai pertanda bahwa islam telah melebur menjadi bagian yang terpisahkan buat masyarakat Indonesia.

\section{REFERENSI}

Al-Faruqi, Isma'il Raji. 1984. Islamisasi Pengetahuan. Penerjemah Anas Mahyiddin. Bandung: Pustaka.

Ahmad N. Permata. 2008. Islamist Party and Democratic Participation. Universität zu Münster

Daud, Wan. 2002. Filsafat Dan Praktik Pendidikan Islam, Johor.

Gazalba, Sidi. 1975. Mesjid pusat Ibadah dan Kebudayaan Islam, Jakarta: Pustaka Antara. 
Jamil, Mohd. Mukmin. 2004. Makna pusat penyebaran Islam di Nusantara, Institut Kajian Sejarah dan patriotisme Malaysia (IKSEP), MAlaka,

Jaelan, Abdul Qadiri. 1999. Sejarah Perjuangan Politik Umat Islam Indonesia, yayasan pengkajian Islam Madinah al-Munawwarah Jakrta,

Kemas Badarudin. 2009. Filsafat Pendidikan Islam: Analisis Pemikiran Prof. Dr. Syed Muhammad Al Attas, Yogyakarta: Pustaka Pelajar

Saefullah. (2017). Sejarah Kebudayaan Islam di Asia Tenggara, Yogyakarta: Pustaka Pelajar

Sardar, Ziauddin. 1998. Jihad Intelektual, Bandung: Risalah Gusti.

Yatim, Badri. 2008. Sejarah Peradaban Islam "dirasah Islamiyah II, Jakarta: Raja Grafindo

Ziauddin Sardar. 1998. Jihad Intelektual: Merumuskan Parameter-parameter Sains Islam, Surabaya: Risalah Gusti https://duniamasjid.islamic-center.or.id https:// seni kaligarafi.or. Id 